\title{
An Empirical Study on Risk Allocation Preference and Potential Disputes of Risk Allocation
}

\author{
ZHAO Hua ${ }^{1, a^{*}}$, JIANG Hui-jie ${ }^{2, b}$ and ZHANG Li-feng ${ }^{3, c}$ \\ ${ }^{1}$ School of Accounting, Wuhan Textile University, Hubei, China \\ ${ }^{2}$ School of Construction and Environmental Engineering, Shenzhen Polytechnic, Guangdong, China \\ ${ }^{3}$ School of Accounting, Wuhan Textile University, Hubei, China

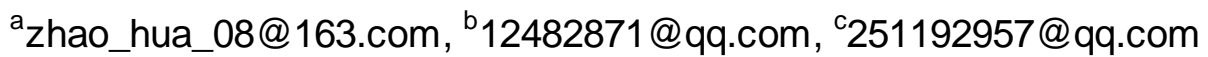

\section{Keywords: Risk Allocation, Risk Allocation Preference, Potential Disputes, Empirical Study}

Abstract: The cognitive differences of different participants on risk allocation preference (RAP) will cause the potential disputes of risk allocation. By questionnaire surveying, the datum of actual RA scheme and its RAP were collected among the owners, the contractors and consultants. The statistical analysis results show that there are higher level consistency between the actual RA and RAP, but the contractors bears too much risks as usual; and for some project risks, the RAP of the owners is different with the contractors' significantly, which results in the contract disputes usually.

\section{Introduction}

A lot of high risk factors exist in the process of project construction [1], both identification and assessment of project risks and selection of the appropriate risk bearer have a significant impact on the project management performance [2]. In theoretically, the owner and contractor cannot conclude the efficient contract terms on risk allocation (RA) quickly unless higher cognitive consistency of risk allocation preference (RAP) exists in the two parties, which shows the RAP is a key issue on how to realize RA reasonably and reduce the potential contract disputes in the practice. Previous studies indicated that some different perceptions on reasonable RA existed not only among different project participants [3-5] but also existed in different members of a same participant [6], and it can be found that the perception differences on RAP also have subjective features [7], which becomes an important source of contract disputes on how to clearly define some risk management responsibilities during the execution of the contract. In this paper, on the basis of literature review some common construction project risk factors are identified, and then the subjective perceptions of RAP on specific risk are collected through questionnaires and analyzed by statistical methods, which have some guidance significance to contracts arrangement on RA before the contract is signed.

\section{Research Methodology}

Study Design. In this paper, the common risk factors in construction project(s) are identified through literature review and case study, and the risk register matrix [8] is shown in No.1 column of Table 1. The RAP means that the subjective perception on reasonable $R A$ is derived from the project management professionals [3][8]. The subjective perception aforementioned is measured by 5-Likert scale, 1 and 5 represents the full liability of specific risk belongs to the contractor and the owner, 2and 4 means that the main liability of specific risk belongs to the contractor and the owner respectively, and 3 means that both sides shared.

Data Collection. The professionals of this survey includes some representative of the owners, the contractors and the engineering consultant units from Beijing, Tianjin, Wuhan, Nanjing, and Shenzhen in China, their main areas of practice are project contract management. For risk factors mentioned above, everyone surveyed need to answer the actual result in most instances and his/her RAP. The investigation lasted four months, 240 questionnaires were sent out and 154 valid questionnaires $(64.2 \%)$ were obtained. In all of 
sample datum, the absolute value of the skewness and the kurtosis is less than 3 and 10 respectively by descriptive statistical analysis, which means the population sample can be accord with normal distribution.

Table 1. The descriptive statistics and variance analys is of actual RA and RAP

\begin{tabular}{|c|c|c|c|c|c|c|c|c|}
\hline \multirow[t]{2}{*}{ Risk factor//No. } & \multirow{2}{*}{$\bar{D} \underset{D}{\stackrel{D}{\vec{D}}}$} & \multicolumn{4}{|c|}{ RAP } & \multicolumn{3}{|c|}{$\begin{array}{l}\text { Mean difference of RAP } \\
\text { between groups Aand B }\end{array}$} \\
\hline & & Sum & $O$ & $C$ & Con & $\mathrm{C}-\mathrm{O}$ & C-Con & O-Con \\
\hline Unknown field conditions $/ / R l$ & 3.3 & 3.6 & 3.6 & 3.6 & 3.6 & .005 & .064 & .059 \\
\hline Bad weather//R2 & 2.9 & 3.3 & 3.0 & 3.6 & 3.1 & $.525 *$ & $.468 *$ & -.057 \\
\hline Natural dis aster//R3 & 3.3 & 3.6 & 3.4 & 3.9 & 3.3 & $.586^{*}$ & $.652 *$ & .066 \\
\hline Other force majeure//R4 & 3.6 & 3.5 & 3.4 & 3.9 & 3.3 & .472 & $.614 *$ & .141 \\
\hline Strike //R5 & 2.0 & 2.2 & 1.9 & 2.4 & 2.2 & .540 & .184 & -.355 \\
\hline Legal changes//R6 & 3.6 & 3.6 & 3.6 & 3.8 & 3.5 & .208 & .273 & .065 \\
\hline Legal / regulatory imperfections //R7 & 3.4 & 3.3 & 3.5 & 3.6 & 2.9 & .069 & $.691 *$ & $.622 *$ \\
\hline Higher HSE requirements//R8 & 3.5 & 3.6 & 3.7 & 3.7 & 3.5 & -.035 & .255 & .289 \\
\hline Public opposition //R9 & 4.2 & 3.8 & 3.8 & 4.1 & 3.5 & .219 & $.595 *$ & .376 \\
\hline Changes in interest rates $/ / R 10$ & 3.0 & 3.1 & 3.1 & 3.2 & 3.0 & .029 & .184 & .155 \\
\hline Inflation //R11 & 2.6 & 3.3 & 3.1 & 3.4 & 3.3 & .277 & .039 & -.238 \\
\hline Tax policy Adjustment //R12 & 2.9 & 3.4 & 3.1 & 3.7 & 3.3 & .551 & .382 & -.170 \\
\hline Shortages of labour/material//R13 & 2.5 & 2.3 & 1.7 & 2.7 & 2.1 & $.943 *$ & $.582 *$ & -.361 \\
\hline Price increasing of labour/material//R14 & 2.8 & 3.1 & 3.0 & 3.6 & 2.7 & $.636 *$ & $.986 *$ & .350 \\
\hline Dispute resolution delays//R 15 & 3.0 & 3.2 & 2.9 & 3.5 & 3.0 & $.587 *$ & $.550 *$ & -.037 \\
\hline Contract documents conflict //R16 & 3.4 & 3.2 & 3.3 & 3.4 & 3.0 & .082 & $.386^{*}$ & .304 \\
\hline Payment delays//R17 & 3.4 & 3.9 & 3.4 & 4.1 & 4.1 & $.745^{*}$ & .061 & $-.68 *$ \\
\hline Unreasonable intervention//R18 & 3.1 & 3.6 & 3.5 & 4.0 & 3.1 & .501 & $.898 *$ & .397 \\
\hline Unclear the scope of work //R19 & 3.1 & 3.7 & 3.3 & 3.9 & 3.7 & $.716 *$ & .302 & -.414 \\
\hline Design defects//R20 & 4.2 & 4.1 & 3.9 & 4.5 & 3.8 & $.566 *$ & $.698 *$ & .132 \\
\hline The scope of work changes //R21 & 4.1 & 3.8 & 3.9 & 4.1 & 3.5 & .155 & $.568 *$ & .413 \\
\hline Construction conditions change//R22 & 3.0 & 3.4 & 2.9 & 3.8 & 3.4 & $.903 *$ & .423 & -.480 \\
\hline Design changes $/ / R 23$ & 4.1 & 4.1 & 3.9 & 4.3 & 3.9 & .316 & .398 & .082 \\
\hline Construction Change//R24 & 3.0 & 2.8 & 2.7 & 3.1 & 2.5 & .439 & $.591 *$ & .152 \\
\hline Site security risks//R25 & 2.3 & 2.5 & 2.2 & 2.7 & 2.5 & .508 & .232 & -.276 \\
\hline Unable to enter the site $/ / R 26$ & 3.5 & 4.0 & 3.7 & 4.5 & 3.6 & $.825 *$ & $.852 *$ & .027 \\
\hline Substandard quality//R27 & 2.1 & 1.6 & 1.4 & 1.7 & 1.7 & .270 & .030 & -.240 \\
\hline Technical specification change//R 28 & 3.3 & 3.4 & 3.7 & 3.5 & 3.1 & -.196 & .425 & $.621 *$ \\
\hline Problems of equipment / materials//R29 & 2.5 & 2.7 & 2.0 & 3.2 & 2.7 & $1.23 *$ & .507 & -.718 \\
\hline Insufficient capacity of contractor//R30 & 2.1 & 1.9 & 1.5 & 1.9 & 2.1 & .365 & -.214 & -.578 \\
\hline Site accident $/ / R 31$ & 2.1 & 1.9 & 1.5 & 2.0 & 2.1 & .478 & -.075 & $-.55^{*}$ \\
\hline Poor communication//R32 & 2.7 & 2.8 & 2.9 & 2.9 & 2.6 & .064 & $.327 *$ & .263 \\
\hline Third party delay / defaul//R33 & 3.3 & 3.0 & 3.0 & 3.2 & 2.7 & .138 & $.457 *$ & .318 \\
\hline Lack of contingency plans//R34 & 2.3 & 2.7 & 2.1 & 2.4 & 3.2 & .303 & $-.72 *$ & $-.99 *$ \\
\hline
\end{tabular}

Notes: (1) $O$-the owner, $C$-the contractor, Con-the consultant, Sum-the population sample. (2)* indicates that it is significant at the level of 0.05. (3) For the meaning of statistical analysis results, the paper constructs the criterion as follows.

A. as for RAP, [1, 1.5] and [4.5,5] represents the full liability of specific risk belongs to the contractor and the owner respectively, $(1.5,2.5]$ and $[3.5,4.5)$ means that the main liability of specific risk belongs to the contractor and the owner respectively, $(2.5,3.5)$ means that both sides shared.

B. as for actualRA, $[0,2.5]$ and $(3.5,5]$ represents the full liability of specific risk belongs to the contractor and the owner respectively, and $(2.5,3.5]$ means that both sides shared.

\section{Empirical Analysis}

Overall Analysis of Actual RA and the RAP. It is a common phenomenon that there are some difference between the actual RA and the RAP of engineering management professionals [6]. Through SPSS statistical software, the results of descriptive statistical analysis are shown in Table 1. The main results are as follows. (1) For some risk factors, the actual RA in most practice case is consistent with the RAP of the population samples analysis, such as R2, R5-R7, R9-R16, R20-R25, R27-R28 and R30-R33. About these risk factors mentioned above, it can be found that the contractors are mainly responsible for the micro-view 
and medium-view risks such as R5, R13, R25, R27, R30, and R32, but the management liabilities of macro-view risks belong to the owners, such as $\mathrm{R} 6$ and $\mathrm{R} 9$, the remaining risk factors are jointly controlled by both parties. (2) But for other risk factors including R1, R3-R4, R8, R17-R19, R26, R29 and R34, there are some significant differences between the actualRA and the RAP. These differences indicate that a clear trend is to increase the risk management liabilities of the owners, and reduce the contractors'.

Analysis of the RAP Based on Variance Analysis. One-way ANOVA is employed to analyze the samples data about the RAP by SPSS 20.0, specifically there are three factor levels including the owners $(O)$, the contractors $(\mathrm{C})$ and the consultants (Con), and the dependent variable is the RAP on specific risk factor. The results of data analyzing are shown as Table 1. According to analysis results of one-way ANOVA, it can be considered that both parties have different subjective perception if the mean difference of RAP between the different groups is significant at the level of 0.05. From the mean difference of RAP between different groups, some interesting conclusions can be inferred out as follows.

A. The owners' RAP on 34 risk factors are consistent with the contractors' at a high level, the significant differences of RAP between two parties exist in 11 risk factors such as R2，R3，R13 R15，R17, R19， R20， R22， R26 and R29.

B. The contractors' RAP have some obvious differences with the consultants' on 17 risk factors, such as R2-R4, R7, R9, R13-R16, R18, R20-R21, R24, R26 and R32-R34.

C. The RAP of the owners and the consultants are quite similar, only for 5 risk factors, their opinions are different, such as R7, R8, R28, R31 and R34.

In summary, as for the subjective perception of the RAP, there are greater consistent existing among the owners, the contractors and the consultants in China. However, this situation cannot indicate that the construction project risks are allocated resonably in practice, many practical reasons can lead to this phenomenon, such as the monopolistic of the owners, intensive competition of the contractor market and decreased demand of project construction, etc.

Potential Disputes on RA between the both Parties. In the project bidding process, the contractor is willing to approve the owner's RA scheme or related contract terms due to a variety of practical reasons, which doesn't indicate that the both parties have same subjective perception on the RAP. The actual RA and the significant difference of the RAP in this survey are shown in Table 2.

Table 2. The statistical analysis of the RAP between the contractors and the owners

\begin{tabular}{|c|c|c|c|c|c|c|c|}
\hline \multirow{3}{*}{ Risk factor//No. } & \multirow{3}{*}{$\begin{array}{c}\text { Actual } \\
\text { RA }\end{array}$} & \multicolumn{6}{|c|}{ RAP } \\
\hline & & \multicolumn{3}{|c|}{ Mean } & \multicolumn{3}{|c|}{ Standard deviation } \\
\hline & & $O$ & $C$ & C-O//Sig. & $O$ & $C$ & Sum \\
\hline Bad weather //R2 & 2.9 & 3.0 & 3.6 & $.525^{*}$ & .976 & .950 & .919 \\
\hline Natural dis aster //R3 & 3.3 & 3.4 & 3.9 & $.586^{*}$ & .988 & .849 & .979 \\
\hline Shortages of labour/material//R13 & 2.5 & 1.7 & 2.7 & $.943^{*}$ & .619 & 1.360 & 1.152 \\
\hline Price increasing of labour/material//R14 & 2.8 & 3.0 & 3.6 & $.636^{*}$ & 1.087 & .865 & 1.133 \\
\hline Dispute resolution delays //R15 & 3.0 & 2.9 & 3.5 & $.587 *$ & .596 & .849 & .783 \\
\hline Payment delays //R17 & 3.4 & 3.4 & 4.1 & $.745^{*}$ & 1.158 & 1.002 & 1.076 \\
\hline Unclear the scope of work //R19 & 3.1 & 3.3 & 3.9 & $.716^{*}$ & .964 & .952 & 1.046 \\
\hline Design defects //R20 & 4.2 & 3.9 & 4.5 & $.566^{*}$ & .928 & .664 & .985 \\
\hline Construction conditions change //R22 & 3.0 & 2.9 & 3.8 & $903^{*}$ & 1.058 & .912 & 1.190 \\
\hline Unable to enter the site //R26 & 3.5 & 3.7 & 4.5 & $.825 *$ & .832 & .731 & .971 \\
\hline Problems of equipment / materials //R29 & 2.5 & 2.0 & 3.2 & $1.225^{*}$ & .928 & 1.369 & 1.477 \\
\hline
\end{tabular}

Notes:(1) $O$-the owner, $C$-the contractor, Sum-the population sample. $C$-O/Sig.-the difference of RAP between the contractors and the owners// Statistical significance. (2) * indicates that it is significant at the level of 0.05. (3)the meaning of statistical analysis results is same as it in Table 1.

The both parties' perception difference maybe the source of the potential contract disputes in the future, and the severity level of the disputes can be measured by comparing the standard deviation of the RAP between the owners and the contractors. In Fig. 1, the horizontal axis represents the RAP standard deviation 
of the population sample, and the ordinate axis shows the mean difference on the RAP between the contractors and the owners which has significant difference at the level of 0.05 . Obviously, the farther the distance from the coordinate origin, the greater the perception difference is. In this survey, the potential RA disputes area can de decomposed into 4 parts in descending order-R29//R22, R23//R14, R17, R19, R26//R3, R20, R2, R15, which indicates the severity level of contract disputes if the owner allocated these risks only from their own cognitive perspective.

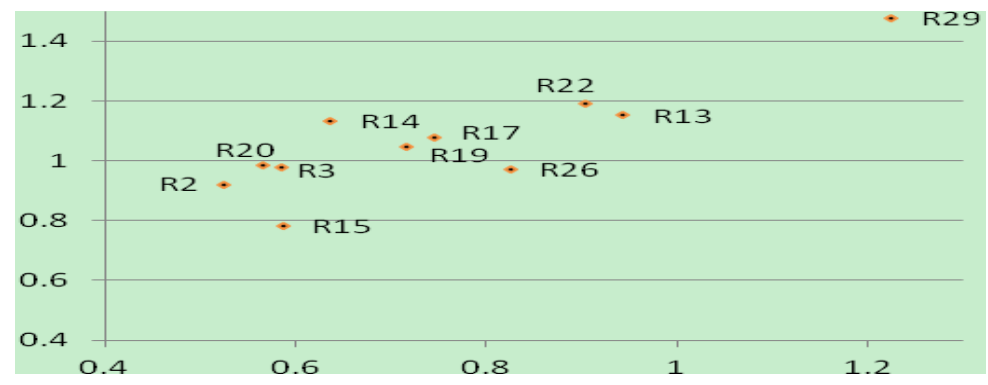

Fig. 1 The potential RA disputes area between the owners and the contractors in construction projects

\section{Summary}

The RA is important to the project management success in construction projects, but the perception of the RAP is subjective, which means how to allocate project risks reasonably is a complex issue. In the project bidding process, the owners have the advantage of the development of procurement rules so that they can be more subjective allocate project risks regardless of the contractor's different perception. However, the perception differences of the RAP not only exist in the both parties, but also it will become an important source of the contract disputes in the future. This paper provides a valid method about how to identify and measure the potential contract disputes on the RA in advance, which has some guidance significance to reasonable RA in practice.

\section{References}

[1] Han,S.H. and Diekmann,J. Juegment-based cross-impact method for predicting cost variance for highly uncertain projects, Journal of Construction Research, 2(2004)171-192.

[2] Tah,J.H.M. and Carr, V. A proposal for construction project risk assessment using fuzzy logic, Construction Management and Economics, 4(2000)491-500.

[3] Francis Hartman, Patrick Snelgrove and Rafi Ashrafi. Effective Wording to Improve Risk Allocation in Lump Sum Contracts, Journal of Construction Engineering and Management, 12(1997)379-388.

[4] Ming-The Wang, M. ASCE, and Hui-Yu Chou. Risk Allocation and Risk Handling of Highway Projects in Taiwan, Journal of Management in Engineering, 4(2003)60-67.

[5] Yongjian Ke, ShouQing Wang and Albert P. C. Chan. Risk Allocation in Public-Private Partnership Infrastructure Projects: Comparative Study, Journal of Infrastructure System, 12(2010)343-351.

[6] M.Motiar Rahman \& M. M. Kumarswamy. Risk management trends in the construction industry: moving towards joint risk management, Engineering, Construction and Architectural Management, 2(2002)131-151.

[7] KE Yong-jian, Equitable Risk Allocation in China PPP Projects, D. Peking, Tsinghua University, 2010.

[8] Athena Roumboutsos, Konstantinos P. Anagnostopoulos. Public-private partnership projects in Greece: risk ranking and preferred risk allocation, Construction Management and Economics, 3(2008)751-763. 